\title{
Women and foreign students in teams: the key players
}

\section{Rosella Nicolini}

Departament d'Economia Aplicada - Universitat Autònoma de Barcelona, Spain.

\begin{abstract}
The aim of this proposal is to present a teaching experiment that has been in use since the academic year 2012-2013. The experiment concerns the introduction of a norm to direct the self-assessment of individual participation in the making of group reports. The presence of this norm can limit potential free-riding or conflicts inside each team. Statistical results from more than 400 students who participated in this experiment confirm that this norm was effective in reducing misleading individual behavior. In addition, this effect turns out to be associated with the presence of women and/or students from abroad in each group.
\end{abstract}

Keywords: Norm; Team work; Exchange students; Women.

*** This document includes ideas, opinions, and conclusions drawn by the author, and they do not express the views of the UAB. Any error is the responsibility of the author. 


\section{Introduction}

The teaching experiment we discuss in this study has been in place since the academic year 2012-2013. It is addressed to activities subject to grading for the course External Trade (Comerç exterior) in the Faculty of Business and Economics at Universitat Autònoma de Barcelona.

The material discussed in the course aims at introducing students to basic knowledge of contracts widely used in international trade as well as administrative practices. The teaching process provides opportunities for students to produce group reports as part of their learning process. In particular, the group activity is thought to develop transversal skills as stated in the teaching guide.

This course is taught in both Spanish/Catalan and English and is credited towards a degree in Administration and Business Economics. It is an elective course during the first term (September-January) and is usually taken by local students during the last year of their degree as well as by international students visiting UAB under the patronage of the ERASMUS program or other agreements signed with foreign universities.

The School of Business and Economics at $\mathrm{UAB}$ is a pro-active institution with approximately 200 incoming students each year (for one or two terms). They account for approximately $50-60 \%$ of students enrolled in English-group teaching. ${ }^{1}$

Students are expected to create and present a group report, which accounts for $15 \%$ of their final grade. All required information about the content and the structure of this report is in the guidelines posted on the course webpage. Students are required to meet some milestones in making the document. The lecturer of the group supervises their jobs. Before introducing the norm (to be discussed in the next section), the lecturer was often required to solve conflicts among group members and, similarly, he/she received several complaints about free-riding or misleading behavior of some group members. These situations are discussed in Del Canto et al. (2009). The introduction of the norm was thought to reduce these problems and identify the potential patterns to limit the problems resulting from incomplete control over the process of report making.

As we will describe in this paper, the adoption of a norm was successful not only because it limited group conflicts, but also because it allowed some interesting conclusions to be drawn about the group composition and their expected behavior (something that will be implemented in the next step of this experiment). The presence of women and foreign students seems to be a deterrent to misleading declarations.

\footnotetext{
${ }^{1}$ A complete description of the internationalization policy of the school can be found in Nicolini and Roig (2016).
} 
The structure of the document is as follows. In Section 2, we describe the structure and organization of the teaching experiment, and in Section 3 we present and discuss some numerical evidence and statistical results. Finally, Section 4 concludes.

\section{The Teaching Experiment: A Description}

This teaching experiment has been carried out from the academic year 2012-2013 up to the most recent year (2018-2019). Given its implementation over time, it has been possible to gather data and build an original database allowing the identification of some salient features of individual behavior and, then, draw some empirical-ground insights about the best way to organize the team group tasks in order to overcome the drawbacks identified previously.

The tasks to be performed by a team (whose size can vary between two and six persons) require that the team members perform an easy research job to address some questions referring to the internationalization process of a selected product with a representative Spanish brand that is an international exporter of that product. In the webpage for the course, students will find some instructions posted with the different milestone points that they need to include in their document. Once completed, the document is delivered to the lecturer and group members must give a public presentation of the most salient content of their research to the other students. The report and presentation are subject to grading, and they jointly contribute to $15 \%$ of the final grade for each student. Students are advised of the grading policy at the initial class meeting. They also know that the percentage included in the joint declaration will be used to tailor proportionally the grade of the team report assigned to each team member. Students learn that although they deliver a joint report, they can receive different scores. In this task, students are required to have an active role in the evaluation process (Bretones, 2008), and they also learn the importance of properly fulfilling all required learning tasks differently than with a classic exam (Alcañiz et al., 2015).

In the making of the group report, the key issues to control for were conflicts among team members and the risk of free-riding behavior. In this respect, an important task for the lecturer is to introduce a device that will allow for tailoring the score of the report so that it fits the true participation of each group member. In order to control for this, the lecturer chose as a controlling device a behavioral norm that all students participating in the team activity must fulfill. This norm is that when delivering the final version of the group project, each team also has to deliver a joint declaration (signed by all members of the group) in which each member has to quantify (in percentage) and declare her/his participation in the making of the report. The fact that this declaration must be signed by all the members of the group implies that they all agree with the self-declared individual 
percentage quotas. The rationale behind this requirement is to create a psychological pressure among team members by means of reciprocal control in a way that will reveal private information rather that hiding it. This behavioral association between cooperation and trust among team member has been widely studied in the theory of incentives (La Porta et al., 1997). There is common agreement that the introduction of a norm as a tool for controlling deviating incentives is more effective than any other type of punishments in limiting unfair behavior (Gneezy \& Rustichini, 2000; Acemoglu \& Jackson, 2017).

\section{Empirical evidence and statistical results}

The introduction of this norm was successful. This requirement eliminated any conflict situation that was previously reported to the lecturer (the person expected to solve them). In the same way, it also helped students by making them aware of the importance of performing the joint task under the best collaborative conditions. But, beyond these qualitative results, it is also important to analyze from a quantitative perspective the potential insights this experiment can deliver into creating the most effective team to fulfill this task.

The collection of data referring to this teaching experiment began in 2012-2013 and covered seven academic years involving 439 students organized in 143 groups. ${ }^{2}$ The definition of the selected variables is in Table 1.

Table 1. Variable definitions

\begin{tabular}{|c|c|}
\hline Variable & Definition \\
\hline Group size & Number of individuals belonging to the same group \\
\hline Gender & Dichotomous variable (1: Female; 0 Male) \\
\hline Exchange students & $\begin{array}{l}\text { Dichotomous variable (1: Erasmus or other exchange students; } 0 \\
\text { otherwise) }\end{array}$ \\
\hline $\begin{array}{l}\text { Gender exchange } \\
\text { students }\end{array}$ & $\begin{array}{l}\text { Dichotomous variable (1: Female \& Erasmus or other exchange students; } \\
0 \text { otherwise) }\end{array}$ \\
\hline Uniform declaration & $\begin{array}{l}\text { Dichotomous variable (1: All group members declare the same } \\
\text { participation to the group report; } 0 \text { otherwise) }\end{array}$ \\
\hline
\end{tabular}

Some preliminary statistics help to elucidate the distinguishing features of this group of students (Table 2).

\footnotetext{
2 In the statistics, some observations are missing because students or the official records of the faculty did not report complete information. All statistical results are produced using STATA14 software.
} 
In our data, the presence of women (gender) and foreign students (exchange students) accounts for $56 \%$ and $54 \%$ of the sample, respectively. The average size of the group (group size) is about three, and the percentage of declaration in which the members declare an identical share of participation in the making of the group report (uniform distribution) is about $77 \%$, while in $23 \%$ of the cases the students delivered non-uniform declarations. ${ }^{3}$

Table 2. Descriptive statistics

\begin{tabular}{cccc}
\hline Variables & Obs & Mean & Std Deviation \\
\hline Group size & 439 & 3.35 & 1.01 \\
Gender & 438 & 0.56 & 0.49 \\
Exchange students & 439 & 0.54 & 0.50 \\
$\begin{array}{c}\text { Gender exchange } \\
\text { students }\end{array}$ & 438 & 0.31 & 0.46 \\
Uniform declaration & 418 & 0.77 & 0.42 \\
\hline
\end{tabular}

Source: Own elaboration.

As for a further preliminary inspection of the most salient features, we perform a simple exploratory exercise with the aim to identify the existing statistically significant correlations. This exercise consists in computing the correlation between each couple of variables jointly with its correspondent statistical significance (Table 3).

Table 3. Correlations

\begin{tabular}{ccccc}
\hline Variables & Gender & $\begin{array}{c}\text { Uniform } \\
\text { Declaraion }\end{array}$ & $\begin{array}{c}\text { Exchange } \\
\text { Students }\end{array}$ & $\begin{array}{c}\text { Gender } \\
\text { Exchange } \\
\text { Students }\end{array}$ \\
\hline Gender & 1 & $\mathbf{- 0 . 0 8 *}$ & 0.05 & $\mathbf{0 . 6 0} * * *$ \\
Uniform declaration & $\mathbf{- 0 . 0 8 *}$ & 1 & $\mathbf{- 0 . 1 4 * * *}$ & $\mathbf{- 0 . 1 4 * * *}$ \\
Exchange students & 0.05 & $\mathbf{- 0 . 1 4 * * *}$ & 1 & $\mathbf{0 . 6 3} * * *$ \\
$\begin{array}{c}\text { Gender exchange } \\
\text { students }\end{array}$ & $\mathbf{0 . 6 0 * * *}$ & $\mathbf{- 0 . 1 4 * * *}$ & $\mathbf{0 . 6 3} * * *$ & 1 \\
\hline
\end{tabular}

Source: Own elaboration. Statistical significance: ***1\%;**5\%;*10\%

Our preliminary data exploration identifies a negative association between the gender dimension or the condition of being a foreign student and the delivery of a uniform

${ }^{3}$ It corresponds to approximately $16 \%$ of the groups. 
declaration. We do not use a specific tool to control for the honesty of the team members when producing the declaration. In case of a uniform declaration in which each team member declares an equal share of participation in the making of the group report, it is likely that this declaration could mask some free-riding problem. Team members are likely to implement direct or indirect compensations to avoid discrimination in the individual grade granted for the group report. In this view, the delivery of a declaration that gives differing percentages for participation of the group members to the making of this report is less likely to hide this type of behavior. Correlation statistics reveal that this building of an agreement among team members is less likely when there is a woman in the group, and the same holds in the case of exchange students. In the case of women, this result can be associated with a natural aptitude and a degree of involvement in the performance of a task with a clearly declared reward (here, the grade). This type of behavior has been well studied in the literature, especially dealing with the way women work in business teams (Bohnet, 2016). As for the case of exchange students, two arguments can be put forward to understand this phenomenon. One refers to a simple environmental situation: incoming students from foreign universities spend one or two terms at UAB in the same academic year. Given that this course is scheduled in the first term, it is quite likely that this group of students has not had the opportunity to form effective social networks (mostly composed by mates) in order to provide alternative incentives (including corruption) for endorsing freeriding behavior, as can happen with natives who have already completed at least three academic years together. ${ }^{4}$ It is also important to take into account the role of culture in the planning of free-riding behavior (Nicolini \& Roig, 2017). Exchange (foreign) students usually bring social values (or norms) with them from their home countries and introduce them into the local culture. Alm and Torgler (2006) extensively discuss important differences in home and host cultures experienced by individuals moving from one country to another and the way they adapt their individual behavior.

In Table 4, we gather the results of estimations about the probability of getting uniform declarations (ones in which students declare that they contributed equally to the preparation of the joint report) on the basis of the two key features (gender and nationality of the students) previously detected..$^{5}$ This probability is obtained as marginal effects. The marginal effect of each independent variable is the probability of success in a probit model (here, delivering a uniform declaration). This probability is evaluated for each observation and the statistic we report is the average of those probabilities.

\footnotetext{
${ }^{4}$ This issue is discussed in Del Canto et al. (2009)

5 These estimations are reached using a probit model taking into account the temporal dimension since our data comes from different waves of students.
} 
Being a woman or a foreign student seems to be a deterrent to the delivery of a declaration that could hide some misleading or free-riding behavior. The joint combination of the previous two features (corresponding to foreign women students) turns out to be more statistically significant, but the size of the coefficient is not statistically different.

Table 4. Probabilities of getting uniform declarations

\begin{tabular}{cccccc}
\hline Variables & $\begin{array}{c}\text { Marginal } \\
\text { Effects }\end{array}$ & Pseudo-R & Time Effects & Observations & \# Equations \\
\hline Gender & $\mathbf{- 0 . 1 1 * * *}$ & 0.08 & YES & 417 & $\mathbf{1}$ \\
\hline $\begin{array}{c}\text { Exchange } \\
\text { students }\end{array}$ & $\mathbf{- 0 . 1 0 * *}$ & 0.07 & YES & 418 & $\mathbf{2}$ \\
\hline $\begin{array}{c}\text { Gender } \\
\text { exchange } \\
\text { students }\end{array}$ & $\mathbf{- 0 . 1 2 * * *}$ & 0.08 & YES & 417 & $\mathbf{3}$ \\
\hline Gender & $\mathbf{- 0 . 1 0 * *}$ & & & & \\
Exchange & $\mathbf{- 0 . 0 9 * *}$ & 0.09 & YES & 417 & $\mathbf{4}$ \\
Students & & & & & \\
\hline
\end{tabular}

Source: Own elaboration. Statistical significance: ***1\%;**5\%;*10\%

Comparing the previous statistical results, we can formulate two relevant conclusions:

1. The presence of exchange students in a group statistically reduces the probability of getting a uniform declaration (in which all members declare an identical participation share in the fulfillment of the group task) that is likely to hide potential free-rider behavior. Therefore, this entails an improvement of the credibility of the joint declaration.

2. The gender dimension is relevant for reducing the suspected free-rider behavior as well. The presence of women makes no uniform declaration more likely to be delivered. Their role does not seem to override the presence of exchange students in the group (Equation 4 in Table 4). When considering the joint presence of women (native or foreign) and foreign students, they are both statistically significant deterrents for uniform declarations, and the size of their coefficients is comparable.

\section{Conclusions}

The device introduced for evaluating the individual involvement and effort in the preparation of a group report is effective. The norm allows for creating psychological peer pressure making students less prone to free-riding behavior. One interesting insight gained from the statistical analysis is the identification of gender and foreign student status as two 
key factors in preventing collusion in the groups. In the previous sections, we argued the potential reason for this outcome is not in the economics or psychology literature, but, instead, it is in the education setting. Once this result has been accounted for, the next step of this teaching experiment will be the adoption of these findings in group creation by requiring the presence of at least one woman or foreign student. The purpose is to evaluate the effectiveness of this decision in reducing the rate of potential false uniform declarations (masking corruption or the existence of parallel aside deals) and put forward our analysis by referring to the quality of the reports. The idea is to assess whether teams with women or foreign students are also the ones that deliver better reports. This second step needs to be planned carefully because we must define and introduce some indices of quality that need to be consistent over time. But this effort is worthwhile as it can improve knowledge about the way to build effective working teams in the classroom.

\section{References}

Acemouglu, D. \& Jackson, M. (2017). Social norms and the enforcement of the law, Journal of the European Economic Association, 15(2), 245-295. doi.org/10.1093/jeea/jvw006

Alcañiz Zanón, M., Chuliá Soler, H., Riera Prunera, C., \& Santolino Prieto, M. (2015). Evaluación formativa entre iguales: una experiencia de mejora competencial en estudiantes de Estadística. @tic. Rivista d'innovació educativa, 15, 46-54. doi.org/10.7203/attic.15.6397

Alm, J. \& Torgler, B. (2006). Culture differences and tax morale in the US and in Europe. Journal of Economic Psychology, 27, 224-246. doi.org/10.1016/j.joep.2005.09.002

Bohnet, I. (2016). What works. Gender Equality by Design. Belknap Press (Harvard University Press).

Bretones Romanes, A. (2008). Participación del alumnado de Educación Superior en su evaluación, Revista de Educación, 347, 181-202.

Del Canto, P., Gallego, I., López, J. M., Mora, J., Reyes, A., Rodríguez, E., Snajeevan, K., Santamaría, E., \& Valero, M. (2009). Conflicto en el trabajo de grupo: dos casos representativos, presented at XV JENUI, Barcelona (available at: http://jenui2009.fib.upc.edu)

Gneezy, U. \& Rustichini, A. (2000). A fine is a price, Journal of Legal Studies, XXIX, 117. doi.org/10.1086/468061

La Porta, R., Lopez-de-Silanes, F., Shleifer, A., \& Vishny, R. W. (1997). Trust in large organizations, American Economic Review, 87(2), 333-338.

Nicolini, R. \& Roig, J.L. (2016). Los estudiantes de intercambio y el control del problema de los polizones en los equipos de trabajo, @tic revista d'innovació educativa, 17, 1-9. doi.org/10.7203/attic.17.8195

Nicolini, R. \& Roig, J.L. (2017). Gender and culture: do they matter for norms?, Applied Economics Letters, 24(19), 1423-1427. doi.org/10.1080/13504851.2017.1343436 